\title{
Metal Elution and Content of Fused Slags Produced from Incinerated Ash
}

\author{
Jun KobaYAshi, ${ }^{*, a, b}$ Ryoichi KIzU, ${ }^{c}$ Kazuyuki Torit, ${ }^{d}$ and Hideo SugrYama ${ }^{b}$ \\ ${ }^{a}$ Department of Health Science, Faculty of Medicine, Kanazawa University; 5-11-80 Kodatsuno, Kanazawa 920-0942, \\ Japan: ${ }^{b}$ Department of Environmental Health, National Institute of Public Health; 4-6-1 Shirokanedai, Minato-ku \\ 108-8638, Japan: ${ }^{c}$ Graduate School of Natural Science and Technology, Kanazawa University; Kakuma-machi, Kanazawa \\ 920-1192, Japan: and ${ }^{d}$ Department of Civil Engineering, Faculty of Engineering, Kanazawa University; 2-40-20 \\ Kodatsuno, Kanazawa 920-8667, Japan.
}

Received June 26, 2004; accepted August 17, 2004; published online August 23, 2004

In recent years, trials to reuse fused slags, obtained through the further treatment of incinerated ash produced in the process of the disposal of garbage or sewer sludge, such as for building materials including bricks, have drawn attention. To establish the safety of using such substances, elution tests for metals and metal contents were investigated in this study. As the result of examining 13 slags, which were made by different methods, little elution of toxic metals was found in the elution tests when water was used as a solvent. However when acid was used, there was a tendency for the elution of many kinds of metals to become greater. On other hand, the results of content measurements showed that arsenic and selenium, which were not seen to be eluted from any of the slags tested, were detected; and that aluminum and manganese existed in the slags in high concentrations.

Key words fused slag; reuse; safety; metal

From the viewpoints of environmental risk mitigation and of the recycling of industrial products, many items conventionally destined for disposal became candidate objects for use as other products. Moreover, the technology utilized in the recovery/processing for reusing materials has been considerably developed, and recently the safety of reusing these materials has become a subject for investigation. Waste materials such as city garbage are thoughtlessly generated in great quantities. In Japan, most such waste undergoes incineration processing and the residue (incinerated ash) is reclaimed. The residual capacities of disposal plants are decreasing every year, and the control of the generation of city garbage, by minimizing production and the recycling of incineration ash has been necessitated out of considerations for the environment. Recently incinerated ashes are being fused even further to create fused slags. This processing of the slags has been tried to create concrete building materials such as bricks for use in sidewalks. ${ }^{1)}$ However, as these products are now beginning to be processed for various practical uses in some cities, it has become necessary to better understand the safety (toxicity and durability) of such products. Since there are various types of melting furnaces and materials, especially such as sewer sludges, it is expected that the character of the slags produced will vary greatly with the place of processing and the season in which they are produced. To date, most investigations have been into the physical aspects of their use; but only from a viewpoint of the density and durability of concrete products prepared from slag for use as building materials. ${ }^{2)}$ Almost no research investigating the chemical components of slag aggregates has been reported. Among the possible chemical components, inorganic substances are considered to be very important. These do not decompose in the fusion process and the mostly remain intact in the end product. It is especially important because metals also have toxic actions. ${ }^{3,4)}$ In this study, in order to check the safety when reusing fused slag as building materials, elution tests and the metal contents were examined using 13 fused slags having different preparation methods and sampling points.

\section{Experimental}

Reagents Standard metal solutions of atomic absorption spectrometry (AAS) grade were purchased from Wako and Kanto Chemicals, and diluted suitably with $0.1 \mathrm{~m}$ nitric acid. Hydrochloric acid (Kanto Chemicals, AAS grade), nitric acid (Wako, toxic metal analysis grade) and hydrofluoric acid (Kanto Chemicals, AAS grade) were used. All water used was refined by the Milli-Q system.

Apparatus Decomposition of slags was performed using microwave decomposition equipment (Milestone MLS-1200MEGA). The metal concentrations in the decomposition liquids and eluates were measured by an AAS (Hitachi Z-8000) with graphite furnace mode. Nine metals were measured (aluminum, arsenic, cadmium, chromium, copper, manganese, lead, selenium and tin), and each measurement condition was optimized according to the manufacturers instruction manual. All containers were washed by acid soaking before use.

Fused Slags In this study, 13 slags in which the fusing (gasification, coke bed, plasma, etc.), cooling (water, air and gradual) and materials (city garbage and sewer sludge) differed were used (Table 1). Water cooling is defined as being dropped in water after fusion; a method that institutes sudden cooling and solidification. Air cooling is defined as being left in air for natural cooling (about $15^{\circ} \mathrm{C} / \mathrm{min}$ ). Gradual cooling is defined as being kept in air at a controlled cooling temperature $\left(1^{\circ} \mathrm{C} / \mathrm{min}\right)$, and thus promoting crystallization.

Elution Testing of Metals Elution tests were performed based by an officially sanctioned method. ${ }^{5)} 3.5 \mathrm{~g}$ of slag was crushed with a pestle in a mortar and passed through two sieves of 8.6 and 60 meshes to be fractioned to three parts. The middle size granule $(0.425-2 \mathrm{~mm} \phi)$ was put into a $50 \mathrm{ml}$ conical tube, and $35 \mathrm{ml}$ water added. The suspended solution was shaken in a mechanical shaker $\left(200 \mathrm{~min}^{-1}, 4 \mathrm{~cm}\right.$ of width) at room temperature for $6 \mathrm{~h}$. After shaking, the supernatant was filtrated with a membrane filter $(0.22 \mu \mathrm{m} \phi$ pore size $)$, and nitric acid was added to $0.1 \mathrm{M}$ acidity. Metals in the eluate were measured by AAS. In addition to using water, elution was also performed using $\mathrm{pH} 4$ nitric acid and $\mathrm{pH} 10$ potassium hydroxide for eluents, simulating acid rain and snow, and soil exudation liquids. Each slag was measured in duplicate and that the examination value was below sensitivity was checked (Al $<0.5 \mathrm{ppb}$; $\mathrm{As}<5 \mathrm{ppb}$; $\mathrm{Cd}<0.05 \mathrm{ppb}$; $\mathrm{Cr}<0.5 \mathrm{ppb}$; $\mathrm{Cu}<0.5 \mathrm{ppb} ; \mathrm{Mn}<0.5 \mathrm{ppb} ; \mathrm{Pb}<1 \mathrm{ppb} ; \mathrm{Se}<10 \mathrm{ppb}$; $\mathrm{Sn}<5 \mathrm{ppb}$ ).

Metal Contents $0.2 \mathrm{~g}$ of slag and $2 \mathrm{ml}$ of hydrochloric, nitric, and hydrofluoric acid were each added into the Teflon decomposition container. This container was applied to the microwave decomposition equipment and sample decomposition performed. The conditions used in the decomposition were a frequency of $2450 \mathrm{MHz}\left(12.25 \mathrm{~cm}\right.$ wavelength), $120^{\circ} \mathrm{C}, 60 \mathrm{~min}$, and $400 \mathrm{~W}$. The device decompresses the container so that it undergoes above 110 atmospheric pressures. The sample after decomposition is transferred to another tube, and the supernatant fluid moves to another tube after centrifuging at $3000 \mathrm{rpm}$ for $10 \mathrm{~min}$. Centrifuging was repeated after adding of water to the remainder, and a decomposition liquid of $20 \mathrm{ml}$ was prepared. Metals 
in the liquid were measured by AAS.

\section{Results and Discussions}

Metal Elution Of the metals measured, aluminum and chromium were detected in some samples with their extent tending to become higher in an alkaline medium. When the elution test of Slag F was carried out with water, chromium eluted in a high concentration $(68.69 \mathrm{ppb})$ that exceeded environmental quality guidelines $(<50 \mathrm{ppb}$; environmental quality is mainly judged on hexavalent chromium, and here most was thought to be hexavalent). ${ }^{67)}$ Arsenic and selenium were not detected in the eluates (detection limit: As, $5 \mathrm{ppb}$; Se, $10 \mathrm{ppb}$ ). Cadmium was detected only in 2 slags $(\mathrm{B}, \mathrm{C})$, and the values in alkali, water and acid had a tendency for the concentration to become higher in this order. Copper and manganese were detected in most slags, and had a tendency for the concentration to become higher at an acidic elution. Although the elution of lead was confirmed only in some slags, it tended to become higher according to the acidity. It was thought that such differences in metal concentrations in the eluates reflected the materials and preparation methods of the slags, and the character and chemical forms of the metals. $^{8-10)}$ Although the differences of metal elution among the slags was thought to be based on the quality of the garbage used, it was also predicted that the matrix was changed by how the slags were created (fusion, cooling, etc.). Moreover, the elution from the slags of many metals becomes higher if the solution is acid or alkali rather than of water. It was thought that it was also dependent on whether the chemical

Table 1. Kinds of Fused Slags

\begin{tabular}{clll}
\hline \hline Slag & \multicolumn{1}{c}{ Source } & \multicolumn{1}{c}{ Fusion } & Cooling \\
\hline A & Garbage & Heat decomposition gasification & Water \\
B & Sewer sludge & Surface fusion & Water \\
C & Garbage & Plasma & Water \\
D & Sewer sludge & Coke bed & Air \\
E & Garbage & Kiln-type gasification & Water \\
F & Sewer sludge & Coke bed & Water \\
G & Garbage & Coke bed & Gradual \\
H & Garbage & Arc & Water \\
I & Garbage & Surface fusion & Water \\
J & Garbage & Electric resistance & Air \\
K & Sewer sludge & Coke bed & Air \\
L & Sewer sludge & Rotation & Water \\
M & Sewer sludge & Coke bed & Water \\
& & & \\
\hline
\end{tabular}

forms of the metals are anions (aluminum, chromate, etc.) or cations (manganese and others). ${ }^{11)}$

Metal Contents The results were converted into metal quality per slag (ng-mg/g) based on the amount of decomposed slag, the decomposition liquid volume $(20 \mathrm{ml})$ and the metal concentration in the decomposition liquid, which are shown in Table 2. Aluminum, copper and manganese were detected at a sub- $\%$ order in all the samples. The chromium and lead detected were of a ppm order in all the samples; whereas arsenic, selenium and tin were similarly detected in some samples. Cadmium was detected at an order of ppb in decomposition liquids in some samples. Chromium content was high only in Slag A, at about $0.2 \%$. Arsenic was also detected only in this sample. The tin content was the highest in this sample. In Slag B, aluminum content was very high at about $1 \%$. Cadmium content was also high in this sample. Slags $\mathrm{C}$ and $\mathrm{D}$ had cadmium to a similarly high level. In Slag E, cadmium and lead content were high. In Slag F, chromium was the highest, while lead was in Slag I. In Slag L, aluminum content was high, like in Slag B.

Relationship of Elution Process with Metal Contents The calculations of the rate of the concentration in the eluate reflecting the amount in the decomposition liquid (i.e., the elution rate from slag) is shown in Tables $3-5$ for each eluent (water, $\mathrm{pH} 4,10$ ). When water was used as the solvent for elution, aluminum was highly eluted at about 3\% from Slag D. When acid was used, about 2\% was detected from Slag J. When an alkaline solution was used for the eluent, aluminum was eluted at about 4\% from Slag D, 2\% from Slag I, and 1\% from Slag M. Since the rate of aluminum in these slags is high as shown in Table 2, it is expected that slags after an elution test have been changed in their quality (density, etc.). The kinds of slag having higher metal elution will vary with $\mathrm{pH}$, because the location of metal in slag differs and this is reflected in the elution conditions $(\mathrm{pH})$. Similarly, it is thought values measured vary even in the same slag, so sample components differ even by localization. Elution of cadmium from Slag $\mathrm{C}$ resulted in at least $14 \%$ under acidic conditions. Since it turns out that the rate of cadmium in the slag is low, we can anticipate that the quality of the slag is not influenced after the elution test. Considering the effect of the release of toxic metals to the environment, it might be desirable to carry out acid washing (elution by an acid solution), before ash products are used as building materials.

Table 2. Content of Metals in Slags

\begin{tabular}{|c|c|c|c|c|c|c|c|c|c|}
\hline Slag & $\mathrm{Al}(\mathrm{mg} / \mathrm{g})$ & As $(\mu \mathrm{g} / \mathrm{g})$ & $\mathrm{Cd}(\mathrm{ng} / \mathrm{g})$ & $\mathrm{Cr}(\mu \mathrm{g} / \mathrm{g})$ & $\mathrm{Cu}(\mathrm{mg} / \mathrm{g})$ & $\mathrm{Mn}(\mathrm{mg} / \mathrm{g})$ & $\mathrm{Pb}(\mu \mathrm{g} / \mathrm{g})$ & $\operatorname{Se}(\mu \mathrm{g} / \mathrm{g})$ & $\operatorname{Sn}(\mu \mathrm{g} / \mathrm{g})$ \\
\hline A & $1.04-1.21$ & $0.70-0.88$ & $<5$ & $1849.97-2035.96$ & $1.61-2.44$ & $1.78-2.26$ & $52.54-56.74$ & $<1-1.33$ & $8.27-17.37$ \\
\hline B & $9.80-12.76$ & $<0.5$ & $402.30-410.37$ & $416.02-425.13$ & $1.13-1.16$ & $1.92-2.00$ & $8.05-8.56$ & $<1$ & $8.05-8.79$ \\
\hline $\mathrm{C}$ & $0.90-1.11$ & $<0.5$ & $34.34-50.56$ & $208.96-251.28$ & $0.62-0.66$ & $1.13-1.40$ & $21.45-25.78$ & $<1$ & $2.43-2.68$ \\
\hline $\mathrm{D}$ & $0.37-0.46$ & $<0.5$ & $290.04-436.48$ & $15.53-21.25$ & $0.31-0.34$ & $0.66-0.73$ & $23.84-29.92$ & $<1$ & $8.31-11.69$ \\
\hline $\mathrm{E}$ & $1.39-1.63$ & $<0.5$ & $342.66-381.52$ & $306.47-390.57$ & $2.14-2.49$ & $0.98-1.05$ & $123.94-127.52$ & $<1$ & $10.45-10.67$ \\
\hline $\mathrm{F}$ & $1.63-1.76$ & $<0.5$ & $<5$ & $5854.15-7452.78$ & $1.61-1.85$ & $1.20-1.30$ & $0.77-1.08$ & $<1$ & $<0.5-0.84$ \\
\hline G & $1.27-2.09$ & $<0.5$ & $<5$ & $113.47-132.25$ & $0.77-1.72$ & $1.31-1.38$ & $7.70-10.00$ & $<1$ & $1.05-1.26$ \\
\hline $\mathrm{H}$ & $1.10-2.34$ & $<0.5$ & $<5$ & $152.02-169.41$ & 0.78 & $1.58-1.73$ & $7.40-7.66$ & $<1$ & $1.75-1.90$ \\
\hline $\mathrm{I}$ & $1.10-2.64$ & $<0.5$ & $31.94-41.41$ & $185.92-221.23$ & $0.89-1.02$ & $1.04-1.08$ & $235.97-240.43$ & $<1$ & $6.77-7.41$ \\
\hline $\mathrm{J}$ & 1.71 & $<0.5$ & $<5$ & $76.06-108.60$ & $0.20-0.22$ & $1.11-1.17$ & $3.03-3.11$ & $<1$ & $0.83-1.33$ \\
\hline $\mathrm{K}$ & $2.36-3.24$ & $<0.5$ & $<5$ & $7.10-15.64$ & 0.08 & $1.19-1.22$ & $0.31-0.33$ & $<1$ & $<0.5-0.66$ \\
\hline $\mathrm{L}$ & $8.57-9.98$ & $<0.5$ & $36.48-37.01$ & $495.44-607.58$ & $0.89-0.90$ & $0.97-1.15$ & $30.88-34.61$ & $<1$ & $2.19-3.14$ \\
\hline M & $1.62-1.92$ & $<0.5$ & $<5$ & $23.17-133.16$ & $0.25-1.82$ & $0.78-0.86$ & $0.21-0.28$ & $<1$ & $<0.5-0.67$ \\
\hline
\end{tabular}


Table 3. Elution Rate of Metals from Slags (Water)

\begin{tabular}{|c|c|c|c|c|c|c|c|c|c|}
\hline \multirow{2}{*}{ Slag } & \multicolumn{9}{|c|}{ Elution (\%) } \\
\hline & $\mathrm{Al}$ & As & $\mathrm{Cd}$ & $\mathrm{Cr}$ & $\mathrm{Cu}$ & $\mathrm{Mn}$ & $\mathrm{Pb}$ & $\mathrm{Se}$ & $\mathrm{Sn}$ \\
\hline A & 0.013 & n.d. & n.d., n.c. & 0.001 & 0.003 & 0.007 & n.d. & n.d., n.c. & n.d. \\
\hline B & n.d. & n.d., n.c. & n.d. & n.d. & 0.003 & 0.005 & n.d. & n.d., n.c. & n.d. \\
\hline $\mathrm{C}$ & 0.183 & n.d., n.c. & 2.550 & n.d. & 0.004 & 0.017 & n.d. & n.d., n.c. & n.d. \\
\hline $\mathrm{D}$ & 3.002 & n.d., n.c. & n.d. & n.d. & 0.004 & 0.001 & n.d. & n.d., n.c. & n.d. \\
\hline E & 0.084 & n.d., n.c. & n.d. & 0.004 & 0.011 & 0.006 & n.d. & n.d., n.c. & n.d. \\
\hline $\mathrm{F}$ & 0.177 & n.d., n.c. & n.d., n.c. & 0.010 & 0.125 & 0.024 & 1.398 & n.d., n.c. & n.d., n.c. \\
\hline G & 0.631 & n.d., n.c. & n.d., n.c. & 0.023 & 0.024 & 0.006 & 0.165 & n.d., n.c. & n.d. \\
\hline $\mathrm{H}$ & n.d. & n.d., n.c. & n.d., n.c. & n.d. & 0.001 & 0.017 & n.d. & n.d., n.c. & n.d. \\
\hline I & 1.143 & n.d., n.c. & n.d. & n.d. & 0.002 & 0.004 & n.d. & n.d., n.c. & n.d. \\
\hline $\mathrm{J}$ & 0.211 & n.d., n.c. & n.d., n.c. & 0.220 & 0.026 & 0.006 & n.d. & n.d., n.c. & n.d. \\
\hline $\mathrm{K}$ & 0.598 & n.d., n.c. & n.d., n.c. & n.d. & 0.079 & 0.004 & n.d. & n.d., n.c. & n.d., n.c. \\
\hline $\mathrm{L}$ & 0.002 & n.d., n.c. & n.d. & n.d. & 0.002 & 0.021 & n.d. & n.d., n.c. & n.d. \\
\hline M & 0.745 & n.d., n.c. & n.d., n.c. & 0.013 & 0.011 & 0.010 & n.d. & n.d., n.c. & n.d., n.c. \\
\hline
\end{tabular}

n.d.: not determined due to few elution of metals; n.c.: not calculated since the metal contents were less than the detemination limits.

Table 4. Elution Rate of Metals from Slags (pH 4)

\begin{tabular}{|c|c|c|c|c|c|c|c|c|c|}
\hline \multirow{2}{*}{ Slag } & \multicolumn{9}{|c|}{ Elution (\%) } \\
\hline & $\mathrm{Al}$ & As & $\mathrm{Cd}$ & $\mathrm{Cr}$ & $\mathrm{Cu}$ & $\mathrm{Mn}$ & $\mathrm{Pb}$ & $\mathrm{Se}$ & Sn \\
\hline A & 0.003 & n.d. & n.d., n.c. & n.d. & 0.070 & 0.045 & 0.031 & n.d., n.c. & n.d. \\
\hline B & 0.002 & n.d., n.c. & 0.278 & n.d. & 0.052 & 0.058 & 0.193 & n.d., n.c. & n.d. \\
\hline $\mathrm{C}$ & 0.177 & n.d., n.c. & 14.498 & 0.008 & 0.402 & 0.029 & 1.713 & n.d., n.c. & n.d. \\
\hline $\mathrm{D}$ & 0.298 & n.d., n.c. & n.d. & n.d. & 0.008 & 0.036 & n.d. & n.d., n.c. & n.d. \\
\hline $\mathrm{E}$ & 0.445 & n.d., n.c. & n.d. & 0.009 & 0.074 & 0.026 & 0.023 & n.d., n.c. & n.d. \\
\hline $\mathrm{F}$ & n.d. & n.d., n.c. & n.d., n.c. & n.d. & 0.033 & 0.139 & n.d. & n.d., n.c. & n.d., n.c. \\
\hline G & 0.080 & n.d., n.c. & n.d., n.c. & 0.008 & 0.023 & 0.111 & n.d. & n.d., n.c. & n.d. \\
\hline $\mathrm{H}$ & 0.547 & n.d., n.c. & n.d., n.c. & 0.010 & 0.341 & 0.045 & 2.517 & n.d., n.c. & n.d. \\
\hline I & 0.242 & n.d., n.c. & n.d. & n.d. & 0.010 & 0.014 & n.d. & n.d., n.c. & n.d. \\
\hline $\mathrm{J}$ & 2.294 & n.d., n.c. & n.d., n.c. & 0.217 & 0.034 & 0.091 & n.d. & n.d., n.c. & n.d. \\
\hline $\mathrm{K}$ & 0.664 & n.d., n.c. & n.d., n.c. & 0.247 & 0.071 & 0.118 & n.d. & n.d., n.c. & n.d., n.c. \\
\hline L & 0.108 & n.d., n.c. & n.d. & 0.021 & 0.084 & 0.097 & 0.041 & n.d., n.c. & n.d. \\
\hline M & 0.094 & n.d., n.c. & n.d., n.c. & 0.026 & 0.012 & 0.048 & n.d. & n.d., n.c. & n.d., n.c. \\
\hline
\end{tabular}

Symbols are the same as in Table 3 .

Table 5. Elution Rate of Metals from Slags ( $\mathrm{pH} 10)$

\begin{tabular}{|c|c|c|c|c|c|c|c|c|c|}
\hline \multirow{2}{*}{ Slag } & \multicolumn{9}{|c|}{ Elution (\%) } \\
\hline & $\mathrm{Al}$ & As & $\mathrm{Cd}$ & $\mathrm{Cr}$ & $\mathrm{Cu}$ & $\mathrm{Mn}$ & $\mathrm{Pb}$ & $\mathrm{Se}$ & $\mathrm{Sn}$ \\
\hline A & 0.392 & n.d. & n.d., n.c. & 0.007 & 0.038 & 0.004 & 0.242 & n.d., n.c. & n.d. \\
\hline B & 0.050 & n.d., n.c. & n.d. & n.d. & 0.016 & 0.003 & n.d. & n.d., n.c. & n.d. \\
\hline $\mathrm{C}$ & 1.614 & n.d., n.c. & 1.653 & 0.035 & 0.102 & 0.007 & 0.495 & n.d., n.c. & n.d. \\
\hline D & 3.902 & n.d., n.c. & n.d. & 0.047 & 0.005 & 0.004 & n.d. & n.d., n.c. & n.d. \\
\hline $\mathrm{E}$ & 0.651 & n.d., n.c. & n.d. & 0.023 & 0.012 & 0.008 & n.d. & n.d., n.c. & n.d. \\
\hline $\mathrm{F}$ & 0.445 & n.d., n.c. & n.d., n.c. & 0.005 & 0.027 & 0.005 & n.d. & n.d., n.c. & n.d., n.c. \\
\hline $\mathrm{G}$ & 0.506 & n.d., n.c. & n.d., n.c. & 0.009 & 0.010 & 0.002 & n.d. & n.d., n.c. & n.d. \\
\hline $\mathrm{H}$ & 0.374 & n.d., n.c. & n.d., n.c. & 0.018 & 0.063 & 0.009 & 1.453 & n.d., n.c. & n.d. \\
\hline I & 1.759 & n.d., n.c. & n.d. & 0.016 & 0.016 & 0.004 & 0.016 & n.d., n.c. & n.d. \\
\hline $\mathrm{J}$ & 0.404 & n.d., n.c. & n.d., n.c. & 0.006 & 0.023 & 0.002 & n.d. & n.d., n.c. & n.d. \\
\hline K & 0.554 & n.d., n.c. & n.d., n.c. & n.d. & 0.017 & 0.002 & n.d. & n.d., n.c. & n.d., n.c. \\
\hline $\mathrm{L}$ & 0.025 & n.d., n.c. & n.d. & n.d. & 0.007 & 0.004 & n.d. & n.d., n.c. & n.d. \\
\hline M & 1.046 & n.d., n.c. & n.d., n.c. & n.d., n.c. & 0.002 & 0.007 & n.d. & n.d., n.c. & n.d., n.c. \\
\hline
\end{tabular}

Symbols are the same as in Table 3 .

\section{Conclusion}

The safety of the slag produced from processed waste was investigated. Although there was very little elution of all metals tested for when water was used as a solvent in the metal elution tests, it became clear that higher concentrations of metal were eluted when acid and alkali solutions were used for the tests. The rates were low in many cases compared with the actual contents of the slags, but there was a 
possibility that the eluted amounts would increase under severer conditions ( $\mathrm{pH}$, temperature, time, etc.). This is an important point in building materials (in which it is desirable that the physical properties do not change) and for effects on the environment (where it is desirable that toxic metals are not eluted). ${ }^{13-15)}$ Utilizing an officially sanctioned method, the elution tests performed mainly used water, and only a few metals (arsenic, cadmium, hexavalent chromium, mercury, lead and selenium) were evaluated. Further, the evaluations here were not carried out considering changes in the physical character of the slags after being in contact with rain or soil exudation liquids. Future examinations about the long-term effects of elution by acids and alkalis, along with the chemical forms of the metals, and taking toxicity into consideration, will be required.

Acknowledgements This research was supported by a grant-in-aid for the Ishikawa Area Industry-Government-Academic Cooperation Abundance Creation Research Project "Hotto Meruto" in 2001.

\section{References}

1) Acosta A., Iglesias I., Aineto M., Romero M., Rincon J. M., Waste
Manag., 22, 887-891 (2002).

2) Lin K. L., Wang K. S., Tzeng B. Y., Lin C. Y., Waste Manag. Res., 21 , $567-574$ (2003).

3) Kobayashi J., Miyazaki M., Chem. Pharm. Bull., 41, 919-922 (1993).

4) Kobayashi J., Yamada H., Morishita M., Yajima T., Anal. Sci., 9, $821-$ 827 (1993).

5) Notification Concerning Soil Pollution (No. 46 of 1991; Promulgated on August 23, 1991)., Environmental Quality Standards for Soil Pollution, Ministry of the Environment Japan.

6) Loyaux-Lawniczak S., Lecomte P., Ehrhardt J. J., Environ. Sci. Technol., 35, 1350-1357 (2001).

7) Pillay K., von Blottnitz H., Petersen J., Chemosphere, 52, 1771-1779 (2003).

8) Kraushaar M., Noll R., Schmitz H. U., Appl. Spectrosc., 57, 12821287 (2003).

9) Kobayashi J., Kizu R., J. Health Sci., 47, 460-463 (2001).

10) Kobayashi J., J. Health Sci., 47, 502-507 (2001).

11) Kobayashi J., Miyazaki M., Hokuriku J. Public Health, 21, 51-55 (1995).

12) Reich J., Waste Manag. Res., 21, 110-118 (2003).

13) Bunzl K., Trautmannsheimer M., Schramel P., Reifenhauser W., J. Environ. Qual., 30, 934-939 (2001).

14) Curkovic L., Cerjan-Stefanovic S., Rastovean-Mioe A., Water Res., 35, 3436-3440 (2001).

15) Shen H., Forssberg E., Waste Manag., 23, 933-949 (2003). 